\title{
Savings Habit Among Individuals in the Informal Sector: A Case Study of Gbegbeyishie Fishing Community in Ghana
}

\author{
Bismark Addai $^{1}$, Adjei Gyamfi Gyimah ${ }^{2} \&$ Wendy Kumah Boadi Owusu ${ }^{3}$ \\ ${ }^{1}$ School of Management and Economics, University of Electronic Science and Technology of China, Chengdu, \\ P.R. China \\ ${ }^{2}$ Department of Finance, Career Spring Institute, Ghana \\ ${ }^{3}$ Department of Economics (IDL), Kwame Nkrumah University of Science and Technology, Ghana \\ Correspondence: Bismark Addai, School of Management and Economics, University of Electronic Science and \\ Technology of China, Chengdu 610054, P.R. China. E-mail: abismarks@ hotmail.com
}

Received: February 7, 2017

Accepted: February 18, 2017

Online Published: March 30, 2017

doi:10.5539/ijef.v9n4p262

URL: https://doi.org/10.5539/ijef.v9n4p262

\begin{abstract}
Abstact
Savings among individuals in the informal sector is imperatively expedient if they are to have any decent and comfortable living conditions at retirement as savings in the informal sector become the obvious substitute for formal pensions. However, much is not known regarding the savings habits of informal sector, particularly, the fishing communities in Ghana. Apparently, this study investigates into the determinants of savings habit of the informal sector in Ghana, using the case of the Gbegbeyishie Fishing community. The data for the study was obtained through administering questionnaires and interviewing targeted respondents. A 120 sample size was randomly drawn from Gbegbeyishie fishing community in Ghana. This study employs the probit model in estimating the determinants of savings in the informal sector. SPSS and STATA statistical packages were employed in descriptive analysis and estimation of the probit model respectively.

It is glaring in this study that age, gender and income are statistically significant conditions for savings in the informal sector. It is also evincing in this study that Age has a significant negative effect on savings and aging decreases the propensity to save by 0.1577656 . On the other hand, income has statistically significant positive effect on savings and that a one unit change in the income variable increases the propensity to save by 0.1292502 . Also, the probability for a male, all other factors held constant, to save is higher than for a female to save and being a man increases the propensity to save by 0.2024894 . The study also revealed that the main hindrance to savings in the Gbegbeyishie Fishing Community is Low income.

As a result, the authors recommend that men and married people should be targeted whiles paying little attention to the aged in stimulating savings among fishing communities in Ghana. Educational programs could also be organized for the workers in the informal sector as most of the workers have no education which could hinder their income earning capacity and for that matter savings. Further research could also be engineered to consider macro-economic conditions for savings habit in Ghana.
\end{abstract}

Keywords: savings, investment, informal, sector, probit, soci-economic

\section{Introduction}

Savings play an important role in economic growth and development of countries; hence, featuring in both academic and policy discussions. Savings and Investment accumulated domestically provides the means for financing economic projects, which, in turn, affects prospects for economic development. Growth theories have shown that savings is a necessary ingredient to finance investment which will enhance a country's productivity. Financial reserves in the economy insulate the nation against fluctuating international capital. Through the era of low or fluctuating capital, internal savings are essential to finance higher levels of capital formation, thereby contributing to increased productivity and sustained economic development. In increase, higher national saving would help to cut down, rather than worsen, the trade and current account imbalance. The absence of a higher paced national economy, the nation will be confronted with one of two possible outcomes: either the current account deficit will stay high, carrying the risk of feeling increased protectionist pressures; or fail to maximize investment in the local economy just when the proceeds of such investment is high (Luüs, 2005 as cited in 
Owiredu, 2015).

Informal Sectors (ISs) have become an important research area for economists and policymakers in the light of economic development and regional growth. Its importance and significance is due to the fact that informal sector constitute a fundamental basis for building a competitive environment, as well as the basis for forming a middle class society. The informal sector provides flexible and fast satisfaction of consumer needs; it serves as an effective tool for resolving social and economic problems both at national and regional levels. Many individuals and families in both developed and developing countries believe that savings and investment serve as a form of financial security to them.

Savings among the informal sector in Ghana has been found to be really depressing. This usually leads to a miserable way of life of informal sector workers during and after 'voluntary' retirement. Savings constitute a vital origin of calling down the family wealth and assets through structured financial markets and iron away the unanticipated discrepancy in their incomes. Owiredu (2015) argues that an increase in savings is the lone author of building wealth and assets of families while employment opportunities and enhanced growth can be realised through investment.

The trouble of rescuing the poorly remunerated informal sector worker to better the welfare conditions is a major problem facing most welfare economists. On the other hand, in any economy, poor savings and investment capacities is of a major concern since there is a substantial correlation between savings and economic growth (Bremang, 2012).

Though a considerable number of studies have been conducted on savings and investment habits among the informal sector, few studies have focused on the saving and investment habits of the Ghanaian informal sector. Anang et al. (2015) conducted their study in the Tolon-Kumbungu district of Ghana while Oladeji and Ogunrinola (2001) undertook theirs in South-Western Nigeria. Kempson and Finney (2009) reviewed the evidence of savings mainly from the UK perspective as Rikwentishe et al. (2015) looked into saving habits in Taraba state of Nigeria. The foregoing identifies a clear geographical gap of studies on savings habits in Ghana. This study is tailored to address this gap. Also, given that poverty, low living standards and economic hardship among the informal sector is a function of low savings, this study looks into the savings habits of the informal sector in Ghana, employing the case of the Gbegbeyishie community.

Consequently, this study adopts the life cycle theory and the probit model to investigate into how age affects the propensity to save and savings habit in the informal sector while factoring income, education, marital status and gender as control variables.

\subsection{Research Objectives}

This study seeks to establish the rationale, conditions, determinants and hindrances of savings among the informal sector using the case of the small scale fishing community at Gbegbeyishie in Ghana.

This work seeks, among other things, to:

1) To identify the rationale and motivation for savings among the informal sector,

2) To establish the determinants of and conditions for savings among the informal sector,

3) To analyse the impact of age, gender, education and income on savings,

4) To assess the hindrances to savings in the informal sector.

\section{Literature Review}

A diversity of literature relates to the study of savings among the informal sector. The review in this chapter seeks to provide an overview of the existing body of knowledge on issues particularly related to savings among the informal sector, the concept of informal sectors and savings habits. Theories on savings including the life cycle hypothesis have also been reviewed in this section and the study hypothesis thereof.

\subsection{Savings and Investment}

Saving is defined as that part of disposable income which is not spent on consumption (Bime \& Mbanasor, 2011 as cited in Rikwentishe et al., 2015). According to Virani (2012), saving is scarifying the current consumption in order to increase the living standard and fulfilling the daily requirements in future. Saving is an amount of something such as time or money that you do not need to use or spend. It could be used for investment to earn interest (profit) or be used to purchase assets such as buildings. Saving is related to deferring consumption, which is done by the households (individuals), the firms and, the governments. When the interest rate is high, the household will save more money in the bank where entrepreneurs can borrow (Kanjanapon, 2004 as cited in 
Rikwentishe et al., 2015).

It is also observed at almost all the time that it is the household (individual) that saves most, but it is the entrepreneur that invests and the investment of the entrepreneur is got from the saving of the household (Balami, 2006). Since saving of the individual becomes the capital to be invested by the entrepreneurs, the saving and investment habit of individuals go a long way in affecting their chances and the chances of other people to venture into entrepreneurship.

In terms of savings and investments, focusing on the distinction between formal and informal institutions is important for several reasons. Informal finance mechanisms are quite prevalent in low-income countries, and are successful in meeting some specific financial needs. The advantage of informal mechanisms such as rotating-savings-and-credit-associations (ROSCAs) is the ability to overcome some of the information and enforcement problems that often lead to the absence of formal markets.

A further distinction between the formal and informal sectors is that effective monetary policy typically relies on central bank or government control over the banking system. A large informal financial sector may compromise this ability. Research on the connection between informal markets and monetary policy highlights the importance of substitution between the markets.

Carpenter and Jensen (2002) found that bank use in Pakistan is observed even among the poorest households in rural areas. In addition, bank use is as widespread in rural areas as in urban areas, and in fact in rural areas is more commonplace than participation in informal savings committees. In urban areas where physical access to bank branches is more widespread, savings committees dominate bank use. Increases in income lead to a higher rate of participation in both sectors, though at higher levels banks become more widely used than savings committees.

The use of informal finance mechanisms remains at high income levels, but the peak is near the middle of the income distribution. By contrast, bank use increases at higher income levels. These observations collectively suggest that increased income leads to a greater desire to participate in some form of savings institution, but that as income increases more individuals shift to the formal sector. They also found evidence that bank use is strongly influenced by literacy and numeracy, suggesting that attempts to expand the formal financial sector could face severe constraints in countries with low educational attainment and literacy rates.

\subsection{The Informal Sector}

A number of attempts made by different researchers and national authorities or governments to define the concept have resulted in diverse definitions. There are varied definitions of the concept in existing literature. However, most of the definitions revolve around the definitional approach given by Farrel et al. (2000). According to the definitional approach, informal sector is economic activity unrecorded in the official statistics such as the gross domestic product and /or the national income accounts (Farrell et al., 2000).

The informal sector remains the major source of employment across Africa, accounting for 70 percent of employment in Sub-Saharan Africa and 62 percent in North Africa (AfDB, 2013). The dynamism of the informal sector in creating employment and value addition is particularly strong, representing about 80 percent of the total labour force, and contributing about 55 percent of sub-Saharan Africa's GDP. In addition, 9 in 10 informal workers are women and youth, but the lack of social protection, skills upgrading and productive income often trap these groups into poverty and exclusion from economic growth and development, with only about 10 percent of operators benefiting from social protection schemes (AU, 2011).

The informal sector in Ghana is made up of proprietary of micro and small-scaled enterprises. It consists of producers, wholesalers, retailers and consumers. The sector consists of varied activities. In rural Ghana, informal sector work mainly involves agriculture (75\%) (GSS, 2008), fishing and fish processing, agro-based processing. In contrast, more urban workers (43\%) are engaged in non-agricultural activities.

Given that the informal sector often live to retirement without any pensions as posited for the formal sector in the neoclassical theories such as the life cycle hypothesis; savings among the informal sector stands as an imperative expedient if the informal sector is to have any decent income or comfortable living conditions at retirement. Savings is the obvious substitute for formal pensions for the informal sector. This strongly justifies the present study of savings among the informal sector.

\subsection{Empirical Literature on Determinants of Savings}

Existing literature affords a few studies which sought to establish the factors which establish the determinants of savings. Some of these studies are discussed as follows. Anang et al. (2005) carried out a study to investigate the 
factors influencing savings habit of clients of the Bonzali Rural Bank in the Tolon-Kumbungu District of the Northern Ghana using cross-sectional data from 97 randomly selected respondents. The study identified age, gender and marital status of respondents as the factors influencing the decision to save. It also emerged that women save more than men.

Oladeji and Ogunrinola (2001) set out to ascertain the determinants of informal savings in Southwestern Nigeria. The empirical results revealed that savings behaviour in the informal financial sector is affected by income, age, occupation, education and region of residence. They showed that the self-employed, less educated and rural population identified more with informal savings and had a higher informal savings ratio. The two cardinal variables from economic theory (income and age) accounted for the bulk of the variation in the level of informal savings. The results confirmed that marginal propensity to save informally is positive, less than one; but the absolute income hypothesis that marginal propensity to save is greater than average propensity to save in the informal financial sector is contradicted. The result suggested that with a rising income, the average propensity to save informally declines while, presumably, the fraction of income saved increases in the formal sector. Evidence of people becoming thriftier was also established, but savings of this kind was not really and could not have been motivated by the reason of saving-up towards retirement.

Rikwentishe et al. (2015) examined the saving and saving habits of respondents, assessed the effects of saving and saving habit on entrepreneurship development, and assessed the effects of perceived financial wellbeing on entrepreneurship development in Jalingo metropolis, Taraba State, Nigeria. With a total of 130 respondents, the results revealed that $89.7 \%$ do save, $38.4 \%$ for education, $47.6 \%$ save regularly, and $54.7 \%$ save for perceived financial wellbeing, 52.4\% do not collect loan. The correlation results revealed positive relationship between income, savings, perception of financial wellbeing and entrepreneurship development.

Based on the theoretical and empirical review, this study hypothesizes that income level, education, age and marital status will positively affect savings among Gbegbeyishie Fishing Community members.

\subsection{Theoretical Framework and Hypothesis}

Given the objective and nature of this study, a review of theoretical thoughts underpinning savings is in order. Savings theories in existence have included the neoclassical economic theory, psychological and sociological theory, and behavioural economic theory.

Neoclassical economic theory assumes that individuals are rational beings who respond in predictable ways to changes in incentives. From this perspective, there are two broad determinants of individual behaviour: opportunities (or constraints) and individual preferences (Pollak, 1998). Many economic models also assume that individuals have perfect knowledge and access to perfect markets. Individual utility (happiness or satisfaction) is usually assumed to be a function of consumption, and economic models often treat savings as a residual, those resources that remain after consumption decisions are made.

Both life cycle hypothesis (LCH) (Modigliani \& Brumberg, 1954) and the permanent income hypothesis (PIH) (Friedman, 1957 theories assume that individuals and households are concerned about long-term consumption opportunities and therefore explain saving and consumption in terms of expected future income. These theories assume that saving is a way to smooth consumption in the face of income fluctuations.

The life cycle hypothesis is emphasised in this study. The Life-cycle hypothesis made its first appearance in two papers that Modigliani wrote in the early 1950s with a graduate student, Richard Brumberg. The original theory offers a specific account of consumption and saving; but it is derived from fundamental underlying principles that could be used to extend the model to deal with a wide range of issues about consumption and saving (Modigliani \& Brumberg, 1954).

The thrust of the hypothesis is the question of whether empirical data supports the conclusion that people save when they are young and run down their assets when they are old. Some studies have found that the elderly do not dispose of their assets in the way that the hypothesis suggests and indeed that many of the elderly appear to save part of their incomes. Saving for retirement, when we observe it at all, seems to start only in middle-age, and to be insufficient to prevent a sharp fall in consumption at retirement, and such a fall has been well documented (Banks et al., 1998).

Psychological and sociological theories of saving consider additional determinants of saving and asset accumulation, including personality characteristics, motives, aspirations, expectations, and peer and family influences. Some of the propositions emphasize the effects of relatively stable personality characteristics on asset building. Other psychological and sociological propositions assume that saving-related preferences and aspirations are not fixed and in fact seek to explain how motives, aspirations, and expectations are shaped. 
The propositions that emphasize relatively stable personality characteristics typically come from psychology. For example, psychologists have examined the effects of thrift, conscientiousness, emotional stability, autonomy, extraversion, agreeableness, inflexibility, and tough-mindedness on saving (Nyhus \& Webley, 2001).

The emerging behavioural theory of saving attempts to explain how people actually behave with regard to financial matters. Unlike neoclassical economic theory, these models do not assume that people are rational and all-knowing. Behavioural theory attempts to explain (and make assumptions that are consistent with) the behaviour of human beings as human and not necessarily as rational beings.

\subsubsection{Research Hypothesis}

From the theoretical review, the hypothesis for this study is stated as follows:

$\mathrm{H}_{1}$ : There is a positive relationship between age and the propensity to save in the informal sector.

$\mathrm{H}_{0}$ : There is no positive relationship between age and the propensity to save in the informal sector.

\section{Research Methodology}

This chapter outlines and discusses in detail the research design, study area, study population, sample size, sampling techniques, research instruments, data collection procedure, and the tools for data presentation and analysis.

\subsection{Research Design}

The research essentially made use of primary data. This was obtained through administering questionnaires and interviewing targeted respondents. This provided the researchers with first-hand information on issues bordering on the research questions. The study was conducted among fishermen and market women in the fishing community at Gbegbeyishie in Ghana. This study targeted 120 respondents from the fishing community. Random sampling was employed as the sampling technique, owing to the nature of the subject under study. The study mainly employed questionnaires and interviews. The questionnaire was designed to include both closed and open-ended questions. Interviews helped in instances where questionnaires could serve the purpose. A mix of quantitative and qualitative methods of data analyses was employed. Quantitative analysis was applied on the regression model while qualitative analysis was applied on all other non-quantitative questions and variables. Probit regression was also employed in the quantitative model. SPSS and STATA statistical packages were employed in descriptive analysis and estimation of the probit model respectively.

\subsection{Model Specification}

Several models have been employed in prior researches in estimating parameters from binary dependent variables including: the Linear Probability Model (LPM), the Non-linear Probability models: Logit and Probit Models (Maddala, 2005). Although the LPM is simpler, it is deficient because the probability from that model does not always lie between zero resulting in non-normality and heteroskedasticity of the error term (Capps \& Kramer, 1985; Gujarati, 1988). As a result, the probit and logit models have been identified in literature as most appropriate models for binary dependent variables, widely used by researchers (Adeogun et al., 2001, Awunyo-Vitor, 2012). The probit and logit models are similar and yield similar results and the choice dependends on which one is convenient to the researcher (Johnston \& DiNardo, 1997). This study uses the probit model in estimating the determinants of savings at Gbegbeyishie fishing community in Ghana. The decision of a household to save is binary in nature involving the option to save or not. The propensity for respondents to save or not cannot be directly observed and as such becomes the latent dependent variable. For latent dependent variable, the general specification for probit model for dichotomous dependent variable is as follows:

$$
y_{i}{ }^{*}=\beta_{i} x_{i}+\varepsilon_{I}
$$

where $y_{i} *$ denotes the latent propensity to save by respondent $i, \beta$ is the vector of parameters to be estimated, $x_{i}$ is the vector of observed non-random explanatory variables measuring the attributes of respondent $i$, and $\varepsilon_{i}$ is the random error term following standard normal distribution. Since the dependent variable, $y_{i} *$ is unobserved, the observed dependent variable is determined by whether $y_{i}$ exceeds a threshold value or otherwise and this is given as:

$$
y_{i}= \begin{cases}1, & \text { if } y_{i} *>0 \\ 0, & \text { if } y_{i} * \leq 0\end{cases}
$$

Where $y_{i} *$ is the threshold value for $y_{i}$ and is assumed to be normally distributed. The implicit probit model can then be expressed as:

$$
P_{i}=P\left(y_{i}^{*}<y_{i}\right)
$$




$$
\begin{gathered}
P_{i}=P\left(y_{i} *<\beta_{0}+\beta_{i} x_{i j}\right)=F\left(y_{i}\right) \\
P_{i}=F\left(y_{i}\right)=\frac{1}{\sqrt{2 \pi}} \int_{-\infty}^{z_{i}} \exp \frac{s^{2}}{2} d s
\end{gathered}
$$

Where $P_{i}$ is the probability that a person from the fishing community would save or not save; $s$ is a random variable normally distributed with a mean zero and unit variance; $z_{i}$ is the index to be estimated whiles $y_{i}$ and $y_{i}{ }^{*}$ are dependent variable (save) and the threshold value of the dependent variable respectively. The inverse of normal cumulative function is employed in order to estimate the index $z_{i}$. The inverse cumulative function is expressed as follows:

$$
y_{i}=F^{-1}\left(P_{i}\right)=\beta_{0}+\beta_{i} x_{i}+\varepsilon_{I}
$$

Where $F^{-1}$ is the inverse of the normal cumulative function. The parameters of the probit model do not provide direct information about the effect of the changes in the explanatory variable; rather, it provides the probability of saving. The marginal effect of each explanatory variable on the likelihood that a member of the fishing community will save is estimated by taking the partial derivatives of equation (6) with respect to each explanatory variable as shown below:

$$
\frac{\partial P_{i}}{\partial X_{i j}}=\beta_{i j}\left[f\left(z_{i}\right)\right]
$$

Where $P_{i}$ is the mean dependent variable whose value is given in the probit result as:

$$
\begin{gathered}
f\left(z_{i}\right)=F^{-1}\left(P_{i}\right) \\
z_{i=} \beta_{0}+\beta_{1} x_{1}+\beta_{2} x_{2}+\beta_{3} x_{3}+\ldots . .+\beta_{k} x_{k}
\end{gathered}
$$

Apparently, the explicit probit regression model for this study is specified as follows;

$$
z_{i=} \beta_{0}+\beta_{1} \text { Age }+\beta_{2} \text { Gend }+\beta_{3} E d u+\beta_{4} \text { Marry }+\beta_{5} \text { Income }+\varepsilon
$$

Where $z_{i}$ represents the propensity to save (Save $=1,0$ otherwise). Gend is a dummy variable indicating the gender of the respondents sampled for this study; 1 if male, 0 if otherwise. Age is the ages of the respondents in years and Edu is the education level of the respondents. Marry is another dummy variable indicating the marital status of the respondents; 1 if married, 0 if otherwise. Income is the income level in Ghana cedis based on the responses from the questionnaires administered regarding monthly income whiles $\beta_{1}, \beta_{2}, \beta_{3}, \beta_{4}$ and $\beta_{5}$ are the estimated coefficients and $\varepsilon$ is the error term.

\section{Results and Discussion}

This section presents the analysis and interpretation of the results of this study. This includes soci-economic characteristics of the sample, responses on savings, probit results as well as impediments to savings in

\begin{tabular}{|c|c|c|c|c|}
\hline Variables & Type & Frequency & Percentage & Cumulative Percent \\
\hline \multirow[t]{2}{*}{ Gender } & Female & 39 & 32.50 & 32.50 \\
\hline & Male & 81 & 67.50 & 100.00 \\
\hline Total & & 120 & 100.00 & \\
\hline \multirow[t]{5}{*}{ Age (Years) } & $18-30$ & 51 & 42.50 & 42.50 \\
\hline & $31-40$ & 44 & 36.70 & 79.20 \\
\hline & $41-50$ & 17 & 14.20 & 93.30 \\
\hline & $51-60$ & 5 & 4.20 & 97.50 \\
\hline & Above 60 & 3 & 2.50 & 100.00 \\
\hline Total & & 120 & 100.00 & \\
\hline \multirow[t]{3}{*}{ Education } & No education & 65 & 54.20 & 54.20 \\
\hline & Primary Education & 40 & 33.30 & 87.50 \\
\hline & Secondary Education & 10 & 8.30 & 95.80 \\
\hline
\end{tabular}
Gbegbeyishie Fishing Community.

\subsection{Socio-Economic Background of the Respondents}

The socio-economic characteristics of the respondents were analysed according to gender, age, Educational background, marital status and monthly income distribution among the respondents. The results from the survey are presented in Table 1 below.

Table 1. Socio-economic characteristics of the sample 


\begin{tabular}{lcccc}
\hline & Tertiary & 3 & 2.50 & 98.30 \\
Total & Other & 2 & 1.70 & 100.00 \\
\hline Marital Status & & 120 & 100.00 & 37.50 \\
& Single & 45 & 37.50 & 100.00 \\
Total & Married & 75 & 62.50 & 32.50 \\
\hline Income & & 120 & 100.00 & 67.50 \\
(Monthly) & Below 500 & 39 & 32.50 & 86.70 \\
& & & & 93.30 \\
& $501-1000$ & 42 & 35.00 & 100.00 \\
\hline
\end{tabular}

Table 1 shows that more males $81(67.50 \%)$ than females 39 (32.50\%) took part in this study which could also mean the Gbegbeyishie Fishing community is dominated by males. The table also indicate that majority of the respondents engaged in this study were in the 18-30 age group representing as much as $51(42.50 \%)$ of the total response rate. Those who were in the 31-40 age group were represented by $44(36.70 \%)$ whiles those in the 41-50 age bracket were also represented by $17(14.20 \%)$. Respondents in the age bracket of 51-60 were also represented by $5(4.20 \%)$. The table also shows that more than half, $65(54.20 \%)$ of the respondents had no Education. The respondents who have Primary Education were represented by 40 (33.30\%) whiles those who have Tertiary and Other Educational qualifications were also represented by $5(4.20 \%)$. It is also evident that most, $75(62.50 \%)$ of the respondents were married whiles $45(32.50 \%)$ were single. With regards to income distribution, 42 (35.00\%) of the respondents earn between 500 and 1001 Ghana Cedis every month, 39 (32.50\%) earn Below 500 Ghana Ceids every month, 23 (19.20\%) earn between 1000 and 1501 Ghana Cedis every month whiles $16(13.40 \%)$ earn above 1500 Ghana cedis every month. This is a clear indication that most of the respondents engaged in this study are within the age brackets of 18-30 and 31-40 and most of the respondents earn monthly income of less than 1500 Ghana Cedis. The analysis further indicate that most of the respondents were married and have varying financial responsibilities and as such could provide reliable information on household savings.

\subsection{Savings}

Responses were also received from the sample on whether they save or not, the amount they save monthly in Ghana Cedis as well as the motivation for savings which is presented in Table 2.

Table 2. Responses on savings

\begin{tabular}{llccc}
\hline Variables & Type & Frequency & Percentage & Cumulative Percentage \\
\hline Save & No & 29 & 24.20 & 24.20 \\
& Yes & 91 & 75.80 & 100.00 \\
Total & & 120 & 100.00 & 36.30 \\
\hline Monthly savings & Below 500 & 33 & 36.30 & 94.50 \\
& $501-1000$ & 53 & 58.20 & 98.90 \\
& $1001-1500$ & 4 & 4.40 & 100.00 \\
Total & $1501-3000$ & 1 & 1.10 & 37.30 \\
Motivation for saving & Children's needs & 91 & 100.00 & 54.90 \\
& Buy an asset & 34 & 37.30 & 75.80 \\
& Invest & 16 & 17.60 & 84.60 \\
& Build house & 19 & 20.90 & 86.80 \\
& For retirement & 8 & 8.80 & 100.00 \\
\hline
\end{tabular}

Table 2 shows that $91(75.80 \%)$ of the respondents save while $29(24.20 \%)$ do not save. This is a clear indication that majority of the respondents save which could enhance the reliability of the findings in modeling the main 
socio-economic conditions for savings in the informal sector. Out of the 91 respondents who save, 53 (58.20\%) of the respondents save between 500 and 1001 Ghana Cedis every month, $33(36.30 \%)$ save Below 500 Ghana Ceids every month whiles 5 (5.50\%) save above 1001 Ghana cedis every month. The 91 respondents who save were further asked their motivation for saving and the results indicates that $34(37.30 \%)$ save for Children's needs, $19(20.90 \%)$ save for investment, $16(17.60 \%)$ save to buy asset whiles the rest save for building houses, for retirement and precautionary purposes. The analysis suggests that the paramount reason for saving among the Gbegbeyishie Fishing Community is to provide for children's needs.

\subsection{Determinants of Savings}

A probit regression analysis was conducted on socio-economic factors that determine savings in the fishing community and the results have been presented as flows.

Table 3. Probit results for determinants of savings

\begin{tabular}{lccccc}
\hline Independent Variables & Coefficient & Standard Error & z statistics & P value & Marginal Effect \\
\hline Age & -0.6245077 & 0.1684 & -3.71 & 0.000 & 0.1577656 \\
Gender & 0.7210691 & 0.3149799 & 2.29 & 0.022 & 0.2024894 \\
Education & 0.2761491 & 0.1614 & 1.71 & 0.087 & -0.0697619 \\
Marital Status & 0.0979879 & 0.3639165 & 0.33 & 0.743 & 0.0250427 \\
Income & 0.5116306 & 0.1712955 & 3.04 & 0.002 & 0.1292502 \\
\hline Observations & & & 120 & & \\
Log Likelihood & & -49.85 & & \\
Prob $>\mathrm{Chi}^{2}$ & & 0.0001 & & \\
Wald Chi' & & & 27.40 & & \\
Percentage Predicted & & 83.04 & & \\
\hline
\end{tabular}

a) Dependent Variable: Savings

b) Independent Variables: Age, Gender, Education, Marital status, Income.

Note. $\alpha=0.05$, Gender $=$ Gender of respondents $(1$ if Male, 0 if otherwise $)$ Age $=$ Age of respondents, Marital Status $=$ Marital status of the respondents ( 1 if Married, 0 if otherwise), Education = Educational background of the respondents and Income $=$ Monthly income of the respondents in Ghana Cedis.

The Wald test, the likelihood ration test and percentage predicted illustrated in Table 5 depicts a good fit data for modelling determinants of savings from 120 respondents in the Gbegbeyishie Fishing Community. The probability value of 0.000 for the likelihood ratio also indicates that the explanatory variables used in the probit model are appropriate.

From Table 5, Age has a negative coefficient which shows the aged are less likely to save. On the other hand, Education, and Income have positive coefficients which indicates that increasing those variables is more likely to savings in the Fishing Community. In addition, the two dummy variables: Gender and Marital status also have positive coefficients implying Males and those are married are more likely to save. Nonetheless, the table indicates that Education and Marital status are insignificant with p-values of 0.087 and 0.743 respectively. The insignificant $\mathrm{z}$ values for Education and marital status imply that savings in Gbegbeyishie Fishing Community does not depend Education and Marital status. Apparently, the analysis focuses on Age, Gender and Incomes as significant predictors of savings in the fishing community.

Table 5 illustrates that Age has a significant negative coefficient of -0.6245077 (p-value of 0.000 ) which is also confirmed by z-statistic of -3.71 (p-value of 0.000 ). From both coefficient and probability values age has indirect relationship with savings. Similarly, the marginal effect indicates that aging decreases the propensity to save by 0.1577656 . This suggests that there is greater propensity for the young to save than the aged. This is interestingly in consonance with the life-cycle hypothesis reviewed earlier in the study. It is observed that a unit increase in age reduces the likelihood of savings by $15.8 \%$. The finding is not in harmony with Oladeji and Ogunrinola (2001) and Anang et al. (2005) as they found the relation to be positive. Oladeji and Ogunrinola (2001) found the impact of age on the likelihood of saving to be insignificant while Anang et al. (2005) found it to be significant. However, evincing in the table is a statistically significant positive coefficient of 0.5116306 (p-value of 0.002 ) for Income which signifies that increase in household income is more likely to lead to propensity to save. Again, the z-statistic of 3.04 (probability value of 0.002) confirms that an increased household income could lead to greater propensity to save. The marginal effect value for income also shows that a one unit change in the income variable increases the propensity to save by 0.1292502 . However, 
Another significant explanatory variable is the dummy variable; gender. Given a positive coefficient of 0.7210691 , large $\mathrm{z}$ statistic (2.29) and the probability value (0.022), it means that the probability for a male, all other factors held constant, to save is higher than for a female to save. Additionally, being a man increases the propensity to save by 0.2024894 . This also implies that in the fishing community, females are less likely to save than male.

The findings of this study supports the study conducted by Anang et al. (2005) carried out a study to investigate the factors influencing savings habit of clients of the Bonzali Rural Bank identified age, gender and marital status of respondents as the factors influencing the decision to save. The results of this study do not also differ from the findings of a study conducted by Oladeji and Ogunrinola (2001) who set out to ascertain the determinants of informal savings in Southwestern Nigeria and established that savings behaviour in the informal financial sector is affected by income.

\subsection{Hindrances to Savings}

The total sample engaged in this study was asked to indicate the main hindrance to savings form individual perspective and the responses are presented in Table 4.

Table 4. Hindrances to savings among the respondents

\begin{tabular}{lccc}
\hline Hindrance & Frequency & Percentage & Cumulative Percentage \\
\hline Low Income & 86 & 71.70 & 71.70 \\
High dependency ratio & 18 & 15.00 & 86.70 \\
High Expenditure & 7 & 5.80 & 92.50 \\
Poor financial Management & 3 & 2.50 & 95.00 \\
Debt servicing & 2 & 1.70 & 96.70 \\
Total & 4 & 3.30 & 100.00 \\
& 120 & 100.00 & \\
\hline
\end{tabular}

Table 4 illustrates that majority of the respondents engaged in this study; 86 see low income as a major hindrance to savings representing $71.70 \%$ of the total response rate. Those who see high dependency ratio as a hindrance were $18(15.00 \%)$, those who see high expenditure as hindrance were also 7 (5.80\%). Respondents who see Poor financial management as a hindrance were $3(2.50 \%)$ whiles those who see Debt servicing as a hindrance were also represented by $4(3.30 \%)$. This indicates that the main hindrance to savings in the Gbegbeyishie Fishing Community is Low income.

\section{Conclusion and Recommendations}

The study sought to examine the saving habit in informal sector in Ghana using Gbegbeyishie fishing community as a case study. A sample of 120 respondents was used for the study. To achieve the set objectives, frequency tables were employed and probit estimation technique was applied to the dataset.

The study revealed that most of the respondents engaged in this study are within the age brackets of 18-30 and 31-40 and most of the respondents earn monthly income of less than 1500 Ghana Cedis. The analysis further indicate that most of the respondents were married and have varying financial responsibilities and as such could provide reliable information on household savings. The study also revealed that $91(75.80 \%)$ of the respondents save while $29(24.20 \%)$ do not save. Out of the 91 respondents who save, majority, $53(58.20 \%)$ of the respondents save between 500 and 1001 Ghana Cedis every month and the paramount reason for saving among the Gbegbeyishie Fishing Community is to provide for children's needs.

Five socio-economic factors were modelled in this study in determining the conditions for savings habit in the informal sector: gender, age, education, marital status and income. However, only three factor; gender, age and income were statistically significant conditions for savings in the informal sector. It is evincing in this study that Age has a significant negative effect on savings and aging decreases the propensity to save by 0.1577656 . On the other hand, income has statistically significant positive effect on savings and that a one unit change in the income variable increases the propensity to save by 0.1292502 . Also, the probability for a male, all other factors held constant, to save is higher than for a female to save and being a man increases the propensity to save by 0.2024894. The study also revealed that the main hindrance to savings in the Gbegbeyishie Fishing Community is Low income.

As a result, the authors recommend that men and married people should be targeted whiles paying little attention to the aged in stimulating savings in the informal sector in Ghana. Educational programs could also be organized 
for the workers in the informal sector as most of the workers have no education which could hinder their income earning capability and for that matter savings. Further research could also be engineered to consider macro-economic conditions for savings habit in Ghana. Another study could also be conducted to include other informal activities since this study is only limited to fishing in a local community.

\section{References}

Adeogun, O. A., Ajana, A. M., Ayinla, O. A., Yarhere, M. T., \& Adeogun, M. O. (2001). Application of Logit Model in Adoption Decision: A study by Hybrid Clarias State, Nigeria. American Eursian Journal of Agriculture \& Environmental Science, 4(4), 486-472.

AfDB. (2013). African Economic Outlook: Structural Transformation and Natural Resources. Tunis: AfDB

African Union. (2011). Promoting employment for social cohesion and inclusive growth. Addis Ababa: AU.

Anang, B. T., Dawuda, I., \& Imoro, L. (2015). Determinants of Savings Habit Among Clients of Bonzali Rural Bank in the Tolon-Kumbungu District of Ghana. UDS International Journal of Development, 2(2).

Awunyo-Vitor, D. (2012). Determinants of Loan Default among Farmers in Ghana. Journal of Development and Agricultural Economics, 4(13), 339-345.

Balami, D. H. (2006). Microeconomic, Theory and Practice. Maiduguri: Salawe Prints

Banks, J., Blundell, R., \& Tanner, S. (1998). Is there a retirement-savings puzzle? American Economic Review, 88(4), 769-88.

Bime, M. J., \& Mbanasor. (2011). Determinants of informal savings amongst vegetable farmers in North West Region, Cameroon. Journal of Development and Agricultural Economics, 3(12), 588-592. Retrieved from http://www.academicjournals.org/JDAE

Bremang, J. A. (2012). An investigation into the determinants, problems and consequences of low savings in developing (pp. 1-61). Ashesi University College.

Capps, O., \& Kramer. (1985). Analysis of Food Stamps Participation using Qualitative Choice Models. American Journal of Agricultural Economic, 67, 49-59. https://doi.org/10.2307/1240823

Carpenter, S. B., \& Jensen, R. T. (2002). Household Participation in Formal and Informal Savings Mechanisms: Evidence from Pakistan. Review of Development Economics, 6(3), 314-328. Oxford, Blackwell. https://doi.org/10.1111/1467-9361.00157

Economic Commission for Africa. (2014). Economic Report on Africa: Dynamic Industrial Policy in Africa. Addis Ababa: ECA

Farrell, G., Roman, J., \& Matthew, F. (2000). Conceptualizing Shadow Economy. Journal of International Affairs, 53(2), 393.

Fine, D. (2012). Africa at Work: Job Creation and Inclusive Growth. Mckinsey Global Institute, USA.

Friedman, M (1957). A Theory of the Consumption Function. National Bureau of Economic Research. 57 (1), 20-37. Princeton University Press.

Gujarati, D. N. (1988), "Basic Econometrics, 2nd ed, McGraw-Hill Book Company. New York, 580-601

Hart, J. K. (1970). Small-scale Entrepreneurs in Ghana and Development Planning. The Journal of Development Studies, 6(4), 104. https://doi.org/10.1080/00220387008421338

Johnston, J., \& DiNardo, J. (1997). Econometric Methods (p. 12). New York: McGraw Hill,.

Kempson, E., \& Finney, A. (2009). Saving in Lower-Income Households: A Review of the Evidence. Personal Finance Research Centre, University of Bristol.

Maddala, G. S. (2005). Introduction to Econometrics (3rd ed., pp. 318-323). John Wiley \& Sons Ltd. The Atrium, Southern Gate, England.

Modigliani, F., \& Brumberg, R. (1954). Utility Analysis and Aggregate Consumption Functions: An Attempt at Integration. Post Keynesian Economics. New Brunswick. Rutgers University Press.

Nyhus, E. K., \& Webley, P. (2001). The role of personality in household saving and borrowing behaviour. Eur. J. Pers., 15, S85-S103. https://doi.org/10.1002/per.422

Oladeji, S. I., \& Ogunrinola, I. O. (2001). Determinants of Informal Savings in South-Western Nigeria. Savings and Development, 25(2), 225-251. 
Owiredu, A. (2015). Savings Pattern of Public Sector Workers: A case Study of Assin Fosu Police Municipal Division.

Pollak, R. (1998). Notes on How Economists Think. Working Paper No. 3. Joint Centre for Poverty Alleviation. Chicago.

Rikwentishe, R., Pulka, B. M., \& Msheliza, S. K. (2015). The Effects of Saving and Saving Habits on Entrepreneurship. European Journal of Business and Management, 7(23).

Virani, V. (2012). Saving and Investment pattern of school teachers-A study With special reference to Rajkot City, Gujrat. Abhinav National Refereed Journal of research in Commerce and Management, 2(4), 2277-1166.

\section{Copyrights}

Copyright for this article is retained by the author(s), with first publication rights granted to the journal.

This is an open-access article distributed under the terms and conditions of the Creative Commons Attribution license (http://creativecommons.org/licenses/by/4.0/). 